\title{
Ultrastructure and phylogenetic analysis of 'Candidatus Neoehrlichia mikurensis' in the family Anaplasmataceae, isolated from wild rats and found in Ixodes ovatus ticks
}

Correspondence
Yasuko Rikihisa
rikihisa.1@osu.edu

The family Anaplasmataceae currently includes five genera: Ehrlichia, Anaplasma, Neorickettsia, Aegyptianella and Wolbachia (Dumler et al., 2001; Rikihisa et al., 2003). These are all obligately intracellular bacteria that are capable of infecting invertebrates and/or vertebrates. Species of the genera Ehrlichia and Anaplasma include the emerging

Published online ahead of print on 13 April 2004 as DOI 10.1099/ ijs.0.63260-0.

The GenBank/EMBL/DDBJ accession numbers for the 16S rRNA and groESL gene sequences of 'Candidatus Neoehrlichia mikurensis' determined in this study are respectively AB084582 and AB084583 for strain TK4456 ${ }^{R}$ from a wild rat and AB074460 and AB074461 for strain IS58 from I. ovatus ticks.

Detailed primer sequences and phylogenetic tables are available as supplementary material in IJSEM Online. tick-borne human pathogens, such as Ehrlichia chaffeensis and Anaplasma phagocytophilum. As it is difficult to isolate and culture this group of bacteria, the ultrastructure and sequences of conserved genes, such as 16S rRNA, groEL and $g l t A$ (citrate synthase gene), are primarily used to identify and classify this group of bacteria. The present study describes a novel bacterium in the family Anaplasmataceae that was isolated from wild Rattus norvegicus rats by using laboratory rats. The bacteria were found in $R$. norvegicus rats and Ixodes ovatus ticks in Japan and represent a novel genetic cluster, based on phylogenetic analysis of $16 \mathrm{~S}$ rRNA gene sequences that included the bacteria found in $R$. norvegicus rats in China (Pan et al., 2003) and in Ixodes ricinus ticks in the Netherlands (Schouls et al., 1999). Of note, infection of $I$. ricinus ticks with similar bacteria in Baltic regions of Russia was reported by Alekseev et al. (2001). A similar 16S 
rRNA gene sequence and a gltA (621 bp) sequence of the bacterium 'Candidatus Ehrlichia walkerii' in I. ricinus ticks removed from asymptomatic humans in Italy (Brouqui et al., 2003; Sanogo et al., 2003) were reported recently, although whether the humans from whom ticks were removed were infected with this agent was not mentioned. There was no additional information, such as the mammalian host or light or electron microscopic description, available for 'Candidatus E. walkerii'. The groEL sequence had not been determined for any of the above-mentioned bacteria.

Phylogenetic analysis based on groEL sequences of the bacteria in $R$. norvegicus rats and I. ovatus ticks in Japan confirmed this novel cluster in the family Anaplasmataceae by analysis of $16 \mathrm{~S}$ rRNA gene sequences. So far, only $A$. phagocytophilum sensu lato DNA has been detected in wild rats (Neotoma fuscipes) (Castro et al., 2001). This is the first member of the family Anaplasmataceae that is known to infect Rattus species. Establishing a new classification and determining its geographical distribution and tick and mammalian host species would facilitate future diagnosis and identification of this new group of bacteria. According to Murray \& Stackebrandt (1995), 'Candidatus' status is applied to an uncultured species for which relatedness has been determined and phenotypic properties, such as ultrastructure, are made available, but is not formally recognized by the International Code of Nomenclature of Bacteria. Thus, we propose to designate this novel taxon 'Candidatus Neoehrlichia mikurensis'. The well-characterized reference strain is TK4456 ${ }^{\mathrm{R}}$.

The characterization of a novel member of the family Anaplasmataceae in the present study contributes significantly to veterinary medicine and public health by providing a means for differential laboratory diagnostics.

\section{Wild rat and tick specimens}

In total, 15 rats ( $R$. norvegicus) were captured on Mikura Island, southern Japan, in 1998, 1999 and 2003. Animals were anaesthetized with ether to collect blood specimens and after euthanasia, livers and/or spleens were collected aseptically from these rats and frozen at $-20^{\circ} \mathrm{C}$ (specimens collected in 1998 and 1999) or $-80^{\circ} \mathrm{C}$ (specimens collected in 2003) until DNA extraction was performed. Tissues from $R$. norvegicus rats were homogenized in sucrose/phosphate/ glutamate (SPG) buffer $\left(3.8 \mathrm{mM} \quad \mathrm{KH}_{2} \mathrm{PO}_{4}, 7 \cdot 2 \mathrm{mM}\right.$ $\mathrm{K}_{2} \mathrm{HPO}_{4}, 4.9 \mathrm{mM}$ L-glutamate, $218 \mathrm{mM}$ sucrose, $\mathrm{pH} 7 \cdot 2$ ). The $10 \%(\mathrm{w} / \mathrm{v})$ spleen homogenate derived from rat MK01, which was captured in 2003 and was PCR-positive for 'Candidatus Neoehrlichia mikurensis', was inoculated intraperitoneally into five 8-week-old Wister male rats (Japan SLC) at $0.5 \mathrm{ml}$ per rat. To determine the isolation of the bacterium, one rat was killed at each of the following time points: 10, 15, 20, 30 and 60 days after inoculation. Samples were subjected to PCR and electron microscopy. To determine the presence of cross-reacting antibodies, an indirect fluorescent antibody (IFA) test was performed on blood specimens from these rats by using Ehrlichia muris and A. phagocytophilum antigen slides, as described previously (Kawahara et al., 1999; Rikihisa et al., 1997).

A total of 164 adult ticks (I. ovatus, 131 female and 33 male) were collected in Hokkaido, northern Japan, in 2000 and 2001 by flag sampling. Ticks were soaked for $10 \mathrm{~min}$ in a solution of $70 \%$ ethanol with $0 \cdot 1 \%$ povidone/iodine and then rinsed with PBS supplemented with $0 \cdot 5-1 \cdot 0 \%$ calf serum. Fifty-four ticks collected in 2000 were grouped into 18 pools of three ticks each and ground in $0.6 \mathrm{ml} \mathrm{SPG} \mathrm{buffer}$ with a glass pestle on a glass slide with a central depression. Each of the resulting tick homogenates was divided in half. One half was frozen at $-20{ }^{\circ} \mathrm{C}$ and used for DNA extraction and the other half was frozen at $-80^{\circ} \mathrm{C}$ and used to isolate infectious agents. Of 110 ticks that were collected in the year 2001, 80 live ticks were divided vertically from the median line with a sterile razor blade under a dissection microscope. One half of each bisected tick was ground up individually in TRIzol buffer (Invitrogen Life Technologies). The other half of each tick was ground up individually in SPG buffer and frozen at $-80^{\circ} \mathrm{C}$ for isolation of infectious agents. Thirty dead ticks were ground up individually in SPG buffer for PCR. The four tick homogenates that tested positive for 'Candidatus N. mikurensis' by PCR were each inoculated intraperitoneally into two 3-week-old male BALB/c mice (Japan SLC) and two 5-week-old male CB-17/Icr-scid mice (CLEA Japan).

\section{PCR detection of members of the family Anaplasmataceae in wild rats and ticks}

DNA was extracted from the blood, liver and/or spleen of each rat, as well as from tick homogenates, by using a QIAamp DNA mini or tissue kit (Qiagen). RNA was extracted from ticks with TRIzol reagent (Invitrogen Life Technologies) and samples containing 1-5 $\mu$ g RNA were subjected to reverse transcription in a $20 \mu \mathrm{l}$ reaction mixture that contained $10 \mathrm{mM}$ random hexamer, $0.5 \mathrm{mM}$ each dNTP, 1 U RNase inhibitor and $200 \mathrm{U}$ SuperScript II reverse transcriptase (Invitrogen Life Technologies) at $42{ }^{\circ} \mathrm{C}$ for $50 \mathrm{~min}$. The sequences and nucleotide positions of all the primers used for this study are available in Supplementary Table A in IJSEM Online. To amplify the 16S rRNA gene, an initial PCR was performed in a $25 \mu \mathrm{l}$ reaction mixture that contained $2 \mu \mathrm{l}$ extracted DNA or cDNA, forward primer EC12A and reverse primer EC9. All PCR products were sequenced. For nested amplification, a $1 \mu \mathrm{l}$ aliquot of the primary PCR product was used as the template in a second $25 \mu \mathrm{l}$ reaction mixture with the E. muris-specific primer pair EM87f and EM584r, the HF strain-specific primer pair HF51f and HF954r, the A. phagocytophilumspecific primer pair GE9f and GE10r or primer pair IS58-62f and IS58-594r, which were derived from the 16S rRNA gene sequence of 'Candidatus N. mikurensis' strain IS58 that was obtained in this study. Both negative (distilled water) and positive [DNA extracted from E. muris strain HF (Shibata et al., 2000) and A. phagocytophilum strain HZ (Rikihisa 
et al., 1997)] controls were included in each set of amplification reactions.

Of spleen specimens that were isolated from 15 wild rats, seven tested positive for 'Candidatus N. mikurensis' by $16 \mathrm{~S}$ rRNA gene-based PCR. Sequence analysis of DNA samples derived from wild rats showed that all of them (TK0003, TK0005, TK4456 ${ }^{\mathrm{R}}$, TK4457, TK4458, MK01 and MK08) possessed identical sequences of $463 \mathrm{bp}$ (base positions 141-642 of the Escherichia coli 16S rRNA gene). Of 128 pooled or unpooled tick (I. ovatus) specimens (164 ticks), three DNA and two cDNA specimens were positive for 'Candidatus N. mikurensis' and two other DNA and four other cDNA specimens were positive for HF strains, as determined by $16 \mathrm{~S}$ rRNA-based PCR and DNA sequencing analysis. However, the E. muris and A. phagocytophilum $16 \mathrm{~S}$ rRNA genes were not detected by PCR in any of the I. ovatus specimens analysed. Of five $I$. ovatus specimens that were found to be positive for 'Candidatus N. mikurensis', two sequences from samples collected in the year 2000 were identical to each other: IS58 and IS60 shared an identical sequence of $458 \mathrm{bp}$, spanning positions $168-654$ of the $E$. coli $16 \mathrm{~S}$ rRNA gene. Similarly, three sequences from samples collected in the year 2001 (IS091, IS108 and IS168) shared $99 \cdot 6-99 \cdot 8 \%$ identity to IS58 within this region.

\section{Isolation and ultrastructure of 'Candidatus N. mikurensis'}

Spleen and liver specimens were cut into $1 \mathrm{~mm}$ cubes. These tissue and buffy coat specimens from wild rats and experimentally infected rats were fixed and processed as described elsewhere (Rikihisa et al., 1985). Ultrathin sections were stained with uranyl acetate and lead citrate and examined with a Philips model 300 electron microscope at $60 \mathrm{kV}$. Laboratory rats were inoculated with the spleen homogenate from wild rat MK01 that was PCR-positive for 'Candidatus N. mikurensis'. Blood, liver and spleen specimens from these laboratory rats were tested for the 'Candidatus $\mathrm{N}$. mikurensis' $16 \mathrm{~S}$ rRNA gene 10-60 days after inoculation by PCR. Specimens were nested PCR-negative up to day 15 after inoculation and only spleens of days 20 and 30 after inoculation had weak bands (i.e. were weakly positive) by nested PCR. However, blood, liver and spleen specimens from day 60 after inoculation were strongly positive by firstround PCR. Sequences of the resulting PCR products were identical to that of strain TK4456 $6^{\mathrm{R}}$. Transmission electron microscopy of spleen specimens from the rat revealed small cocci in a membrane-bound inclusion within the cytoplasm of endothelial cells of the venous sinuses (Fig. 1). The bacteria contained fine DNA strands and ribosomes and were surrounded by a double bileaflet membrane: an inner membrane and a thin, rippled outer membrane with a narrow periplasmic space, which is characteristic of members of the family Anaplasmataceae (Rikihisa, 1991). The host cells were confirmed as endothelial cells lining the venous sinus, based on the presence of the unique cytoplasmic membrane canalicular system (Uehara \& Miyoshi, 1999). To date, we have been unable to culture the

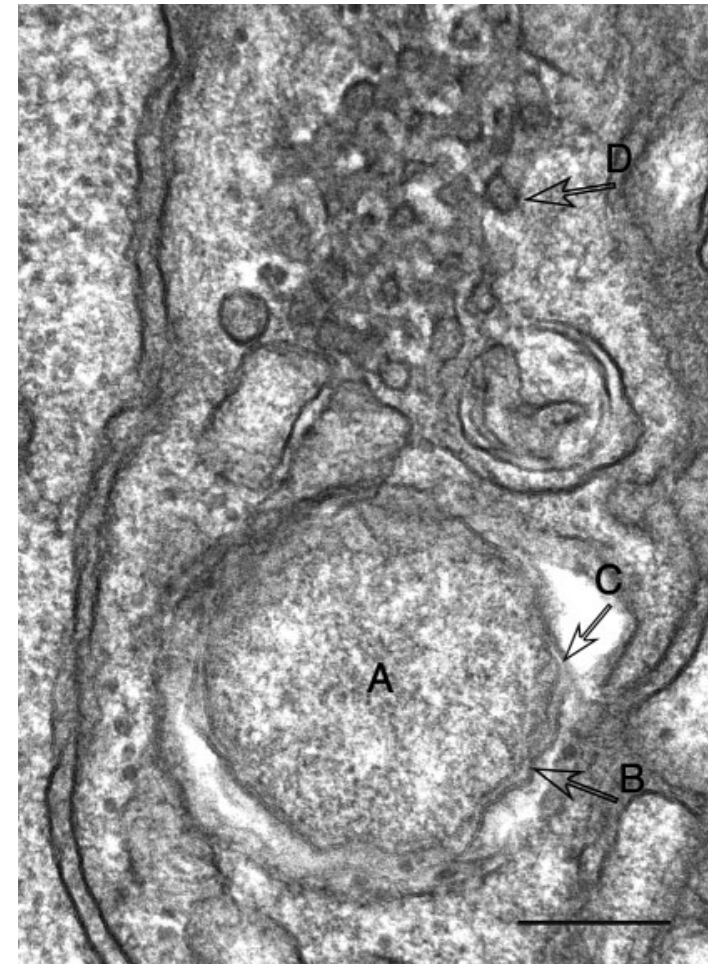

Fig. 1. Transmission electron micrograph of 'Candidatus Neoehrlichia mikurensis'. Organism is present as an inclusion in an endothelial cell lining the splenic sinus of a Wister rat 60 days after inoculation with the spleen homogenate from infected wild rat MK01. The organism contains fine DNA strands and ribosomes (A). Arrows indicate the characteristic thin, rippled, bileaflet outer membrane (B), irregular, narrow periplasmic space between inner and outer membranes (C) and canalicular system of the endothelial cell (D). Bar, $0.3 \mu \mathrm{m}$.

bacterium. None of the serum samples from PCR-positive rats reacted with A. phagocytophilum or E. muris antigens by the IFA test. Four mice inoculated with tick homogenates that were PCR-positive for 'Candidatus N. mikurensis' did not develop any clinical signs and ehrlichial DNA was not detected in their spleens 10 days after inoculation, as determined by PCR analysis.

\section{$16 S$ rRNA gene and groESL sequences of strains TK4456 ${ }^{R}$ and IS58}

We obtained almost-entire 16S rRNA gene sequences of strain TK $4456^{\mathrm{R}}$ from a rat captured in 1999 and strain IS58 from a tick pool collected in 2000, using the first PCR products (approx. $1459 \mathrm{bp}$ ) that were obtained with the EC9 and EC12A primer pair. Primer pairs used for the nested PCR were EC12A and IS58-52r; A17a and EM 584r; Ehr387 and EM924; EM749 and IS58-1345r; and IS58-1203f and EC9. The groESL sequences (approx. $1700 \mathrm{bp)} \mathrm{from}$ both strains TK4456 ${ }^{\mathrm{R}}$ and IS58 were obtained by performing nested PCR with primer pair HS1a and HS6a in the first round and primer pair HS43 and HSVR in the nested 
reaction, as described by Liz et al. (2000). Alternatively, other primer pairs were designed based on the sequence of the PCR product that was obtained with primers HS43 and HSVR, using primers IS58-Gro489f and IS58-Gro908r in the nested reaction. Distance matrices were calculated from DNA sequences with the DNADIST program of the PHYLIP package (version 3.5c). Phylogenetic trees were constructed by neighbour-joining with the NEIGHBOR program of PHYLIP (version 3.5c). TreeView (version 1.5.2) was used to display the phylogenetic trees. Internal nodes were verified by using the SEQBOOT program of PHYLIP (version 3.5c) with 1000 replicates, as described previously (Rikihisa et al., 2003).

The longest 16S rRNA gene sequences (1403 bp, base positions 42-1470 of the E. coli $16 \mathrm{~S}$ rRNA gene) were obtained for strain TK $4456^{\mathrm{R}}$ from a rat from southern Japan and for strain IS58 from a pool of ticks isolated from northern Japan. The 16S rRNA gene sequence of strain TK4456 ${ }^{\mathrm{R}}$ shared $100 \cdot 0,99 \cdot 1,99 \cdot 1,93 \cdot 4,92 \cdot 6,92 \cdot 1,87 \cdot 9$ and $82 \cdot 8 \%$ identity with that of Ehrlichia-like Rattus strain from China (Pan et al., 2003) (GenBank accession no. AY135531), IS58, the Schotti variant (Schouls et al., 1999), Ehrlichia ruminantium, E. chaffeensis, A. phagocytophilum, Wolbachia pipientis and Neorickettsia sennetsu, respectively. When $1403 \mathrm{bp}$ of the 16S rRNA gene sequences were compared (including gaps, positions $42-1470$ of the E. coli $16 S$ rRNA gene), sequences from members of the genera Ehrlichia and Anaplasma were found to be $7 \cdot 8-8 \cdot 9 \%$ divergent from the sequences of strains TK $4456^{\mathrm{R}}$ and IS58, which is nearly equal to the level of divergence in the sequence of the 16S rRNA gene between Ehrlichia and Anaplasma species. A phylogram based on $16 \mathrm{~S}$ rRNA gene sequences showed
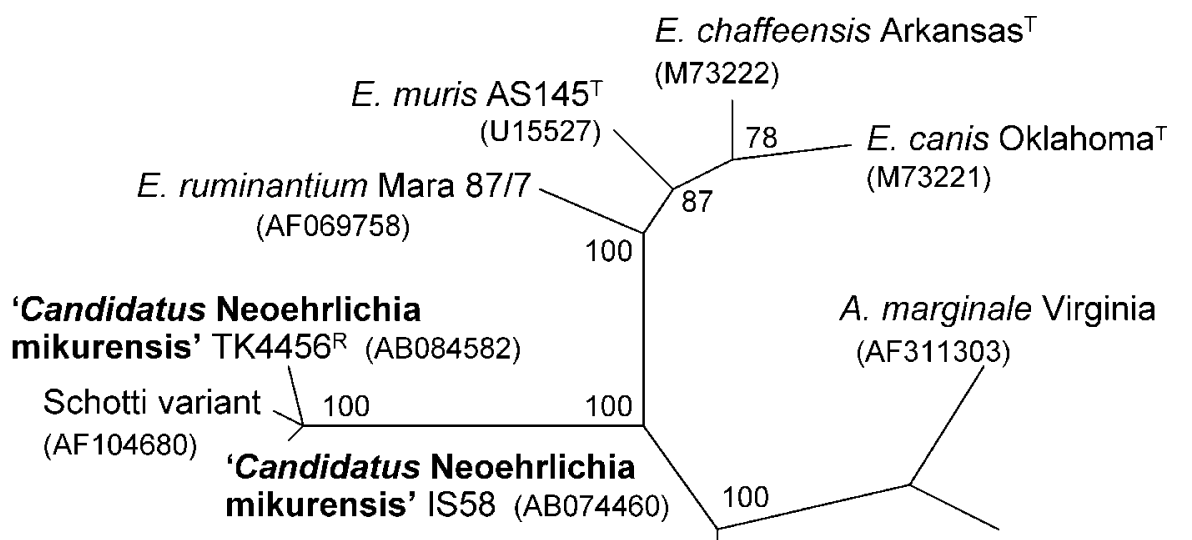

A. marginale Virginia
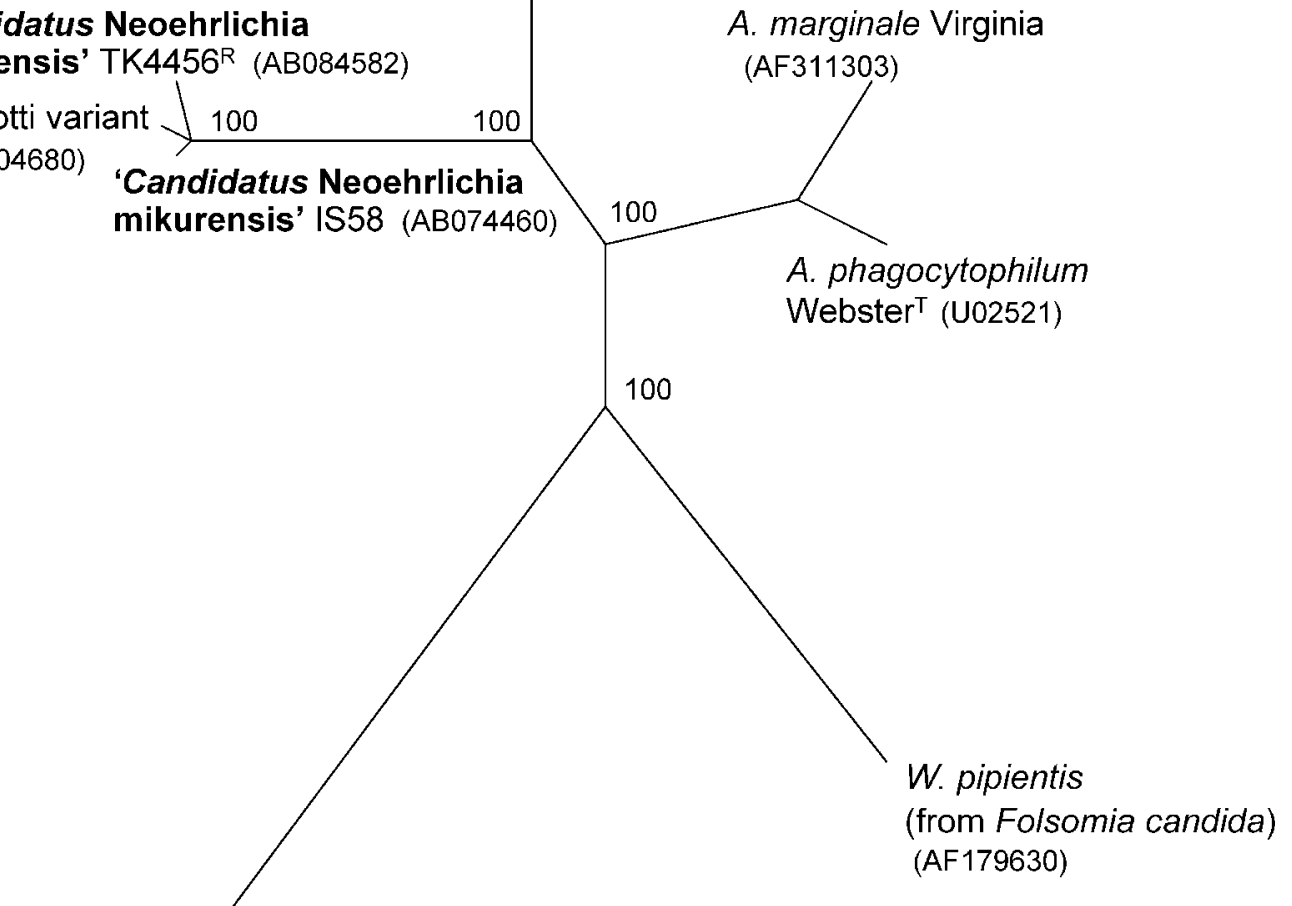

Fig. 2. Phylogram of 'Candidatus Neoehrlichia mikurensis' strains $T K 4456^{R}$ and IS58 and other members of the family Anaplasmataceae, based on $16 \mathrm{~S}$ rRNA gene sequence comparison. GenBank accession numbers are shown in parentheses. Numbers above internal nodes indicate the percentage of 1000 bootstrap replicates that supported the branch. 
that strains TK4456 ${ }^{\mathrm{R}}$ and IS58, together with the Schotti variant and the Ehrlichia-like Rattus strain from China (Pan et al., 2003), create a new cluster between Ehrlichia and Anaplasma species (Fig. 2). The 16S rRNA gene sequence of 'Candidatus E. walkerii' (GenBank accession no. AY098730) is $1281 \mathrm{bp}$, which corresponds to positions 134-1416 of the 16S rRNA gene of A. phagocytophilum Webster $^{\mathrm{T}}$ (GenBank accession no. U02521). The 'Candidatus E. walkerii' sequence lacked most of the divergent sequences that would be useful to classify members of the family Anaplasmataceae and therefore could not be included in the phylogenetic study. However, the 1281 bp sequence from 'Candidatus E. walkerii' was found to share $99 \cdot 1,99 \cdot 1$ and $99 \cdot 0 \%$ identity with the corresponding sequences of the TK $4456^{\mathrm{R}}$, IS58 and Schotti variants, respectively.

No sequence other than the 16S rRNA gene sequence has been determined for the Schotti variant or the Ehrlichia-like

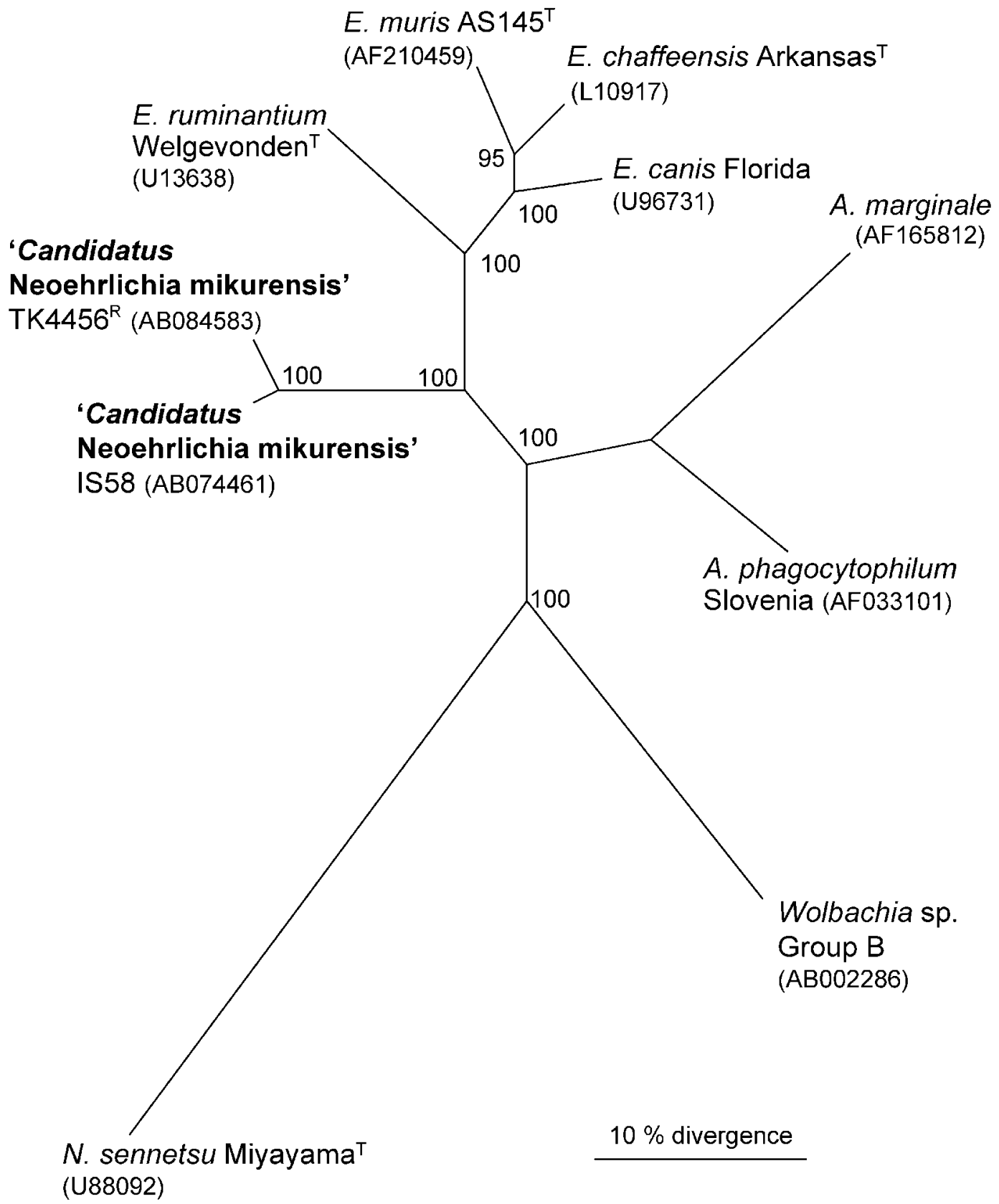

Fig. 3. Phylogram of 'Candidatus Neoehrlichia mikurensis' strains TK4456 ${ }^{\mathrm{R}}$ and IS58 and other members of the family Anaplasmataceae, based on groEL sequence comparison. GenBank accession numbers are shown in parentheses. Numbers above internal nodes indicate the percentage of 1000 bootstrap replicates that supported the branch. 
Rattus strain. Sumner et al. $(1997,2000)$ showed that the phylogram generated from groEL sequences correlates well with the phylogenetic relationships that are inferred from analysis of $16 \mathrm{~S}$ rRNA gene sequences and provides a useful tool for characterizing novel members of the family Anaplasmataceae. New groESL $1327 \mathrm{bp}$ sequences, including groES (13 bp), the intergenic space (91 bp) and groEL $(1223 \mathrm{bp})$, were obtained for strains TK $4456^{\mathrm{R}}$ and IS58. The $1220 \mathrm{bp}$ groEL sequence of $\mathrm{TK}_{4456^{\mathrm{R}}}$ was $99 \cdot 6$, $82 \cdot 5,82 \cdot 1,75 \cdot 8,68 \cdot 6$ and $60 \cdot 2 \%$ identical to those of IS58, E. chaffeensis, E. ruminantium, A. phagocytophilum, Wolbachia sp. and N. sennetsu, respectively. A phylogram based on groEL sequences showed that strains $T K 4456^{\mathrm{R}}$ and IS58 create a novel cluster that is almost equidistant from Ehrlichia and Anaplasma species (Fig. 3).

The present study demonstrates, for the first time, the ultrastructure of a new bacterium isolated from a wild rat. Along with E. ruminantium (Rikihisa, 1991) and an HF strain that is related closely to E. chaffeensis (Okada et al., 2001), 'Candidatus N. mikurensis' is now the third member of the family Anaplasmataceae that is known to infect endothelial cells in vivo. Phylogenetic analysis based on groEL sequences of 'Candidatus N. mikurensis' confirmed the new cluster that was inferred by analysis of $16 \mathrm{~S}$ rRNA gene sequences. For the Schotti variant or the Ehrlichia-like Rattus strain, the results of phylogenetic analysis based on 16S rRNA gene sequences have not been confirmed by sequencing other genes. Brouqui et al. (2003) reported that the gltA sequence ( $621 \mathrm{bp}$ ) of 'Candidatus E. walkerii' (GenBank accession no. AY098729) has $64 \%$ similarity to that of the most closely related organism, E. ruminantium (GenBank accession no. AF304146). This suggests that 'Candidataus E. walkerii' is quite different from other Ehrlichia species.

The 16S rRNA gene sequence of the Schotti variant was detected in an I. ricinus tick in the Netherlands (Schouls et al., 1999); a similar agent was also detected by PCR and subsequent reverse line-blot hybridization (no DNA sequence is available) in I. ricinus ticks in the Baltic regions of Russia (Alekseev et al., 2001) and by PCR and sequencing in $I$. ricinus ticks collected from asymptomatic humans in northern Italy (Brouqui et al., 2003; Sanogo et al., 2003). No mammalian host of these bacteria has been identified in Europe or Russia. I. ovatus is found in various regions of Asia, including Russia and Japan (Yamaguchi et al., 1971), and can be infected with the HF strain (Shibata et al., 2000). I. ricinus, which is distributed widely in Europe, is known to be infected with $A$. phagocytophilum, which infects humans, horses, ruminants and rodents (Dumler et al., 2001). Identification of this novel member of the family Anaplasmataceae would require the use of more specific PCR primers, such as those used in this study, to distinguish this group of bacteria from A. phagocytophilum or the HF strain.

Based on these findings from DNA sequence and electron microscopy analyses, we propose to designate this group of bacteria as 'Candidatus Neoehrlichia mikurensis'.

\section{Description of 'Candidatus Neoehrlichia mikurensis' Kawahara et al. 2004}

Neoehrlichia (Ne.o.ehr.lic'hi.a. Gr. adj. neos new; N.L. fem. n. Ehrlichia name of a bacterial genus; N.L. fem. n. Neoehrlichia a new Ehrlichia; mi.ku.ren'sis. N.L. fem. adj. mikurensis referring to Mikura Island, southern Japan, where the organism was discovered).

Gram-negative pleomorphic cocci of $0 \cdot 5-1 \cdot 2 \mu \mathrm{m}$. Members of the $\alpha$-Proteobacteria, placed phylogenetically within the family Anaplasmataceae. Not cultivated. Grows in membrane-bound inclusions within endothelial cells of the rat. Parasitic to rats and Ixodes ticks. Reference strain is TK4456 ${ }^{\mathrm{R}}$.

'Candidatus Neoehrlichia mikurensis' [( $\alpha$-Proteobacteria $)$ NC; G-; C (approx. 0.5-1.2 $\mu \mathrm{m}$ in diameter); NAS (GenBank no. AB084582 and AB084583), ultrastructure, oligonucleotide sequence complementary to unique region of $16 \mathrm{~S}$ rRNA gene $5^{\prime}$-AATTGTA(G/A)(T/C)TGTAGTTTCTAT-3'; S (Rattus, cytoplasm of endothelial cells; Ixodes ticks); M]. Kawahara et al., this study.

\section{Acknowledgements}

This research was partially supported by grant R01AI47407 from the National Institutes of Health.

\section{References}

Alekseev, A. N., Dubinina, H. V., Van De Pol, I. \& Schouls, L. M. (2001). Identification of Ehrlichia spp. and Borrelia burgdorferi in Ixodes ticks in the Baltic regions of Russia. J Clin Microbiol 39, 2237-2242.

Brouqui, P., Sanogo, Y. O., Caruso, G., Merola, F. \& Raoult, D. (2003). Candidatus Ehrlichia walkerii: a new Ehrlichia detected in Ixodes ricinus tick collected from asymptomatic humans in northern Italy. Ann N Y Acad Sci 990, 134-140.

Castro, M. B., Nicholson, W. L., Kramer, V. L. \& Childs, J. E. (2001). Persistent infection in Neotoma fuscipes (Muridae: Sigmodontinae) with Ehrlichia phagocytophila sensu lato. Am J Trop Med Hyg 65, 261-267.

Dumler, J. S., Barbet, A. F., Bekker, C. P. J., Dasch, G. A., Palmer, G. H., Ray, S. C., Rikihisa, Y. \& Rurangirwa, F. R. (2001). Reorganization of genera in the families Rickettsiaceae and Anaplasmataceae in the order Rickettsiales: unification of some species of Ehrlichia with Anaplasma, Cowdria with Ehrlichia and Ehrlichia with Neorickettsia, descriptions of six new species combinations and designation of Ehrlichia equi and 'HGE agent' as subjective synonyms of Ehrlichia phagocytophila. Int J Syst Evol Microbiol 51, 2145-2165.

Kawahara, M., Ito, T., Suto, C., Shibata, S., Rikihisa, Y., Hara, K. \& Hirai, K. (1999). Comparison of Ehrlichia muris strains isolated from wild mice and ticks and serologic evidence of humans and animals with E. muris as antigen. J Clin Microbiol 37, 1123-1129.

Liz, J. S., Anderes, L., Sumner, J. W., Massung, R. F., Gern, L., Rutti, B. \& Brossard, M. (2000). PCR detection of granulocytic 
ehrlichiae in Ixodes ricinus ticks and wild small mammals in western Switzerland. J Clin Microbiol 38, 1002-1007.

Murray, R. G. E. \& Stackebrandt, E. (1995). Taxonomic note: implementation of the provisional status Candidatus for incompletely described procaryotes. Int $J$ Syst Bacteriol 45, 186-187.

Okada, H., Tajima, T., Kawahara, M. \& Rikihisa, Y. (2001). Ehrlichial proliferation and acute hepatocellular necrosis in immunocompetent mice experimentally infected with the HF strain of Ehrlichia, closely related to Ehrlichia chaffeensis. J Comp Pathol 124, 165-171.

Pan, H., Liu, S., Ma, Y., Tong, S. \& Sun, Y. (2003). Ehrlichia-like organism gene found in small mammals in the suburban district of Guangzhou of China. Ann N Y Acad Sci 990, 107-111.

Rikihisa, Y. (1991). The tribe Ehrlichieae and ehrlichial diseases. Clin Microbiol Rev 4, 286-308.

Rikihisa, Y., Perry, B. D. \& Cordes, D. O. (1985). Ultrastructural study of ehrlichial organisms in the large colons of ponies infected with Potomac horse fever. Infect Immun 49, 505-512.

Rikihisa, Y., Zhi, N., Wormser, G. P., Wen, B., Horowitz, H. W. \& Hechemy, K. E. (1997). Ultrastuctural and antigenic characterization of a granulocytic ehrlichiosis agent directly isolated and stably cultivated from a patient in New York state. J Infect Dis 175, 210-213.

Rikihisa, Y., Zhang, C. \& Christensen, B. M. (2003). Molecular characterization of Aegyptianella pullorum (Rickettsiales, Anaplasmataceae). J Clin Microbiol 41, 5294-5297.
Sanogo, Y. O., Parola, P., Shpynov, S., Camicas, J. L., Brouqui, P., Caruso, G. \& Raoult, D. (2003). Genetic diversity of bacterial agents detected in ticks removed from asymptomatic patients in northeastern Italy. Ann N Y Acad Sci 990, 182-190.

Schouls, L. M., van de Pol, I., Rijpkema, S. G. T. \& Schot, C. S. (1999). Detection and identification of Ehrlichia, Borrelia burgdorferi sensu lato, and Bartonella species in Dutch Ixodes ricinus ticks. J Clin Microbiol 37, 2215-2222.

Shibata, S., Kawahara, M., Rikihisa, Y., Fujita, H., Watanabe, Y., Suto, C. \& Ito, T. (2000). New Ehrlichia species closely related to Ehrlichia chaffeensis isolated from Ixodes ovatus ticks in Japan. J Clin Microbiol 38, 1331-1338.

Sumner, J. W., Nicholson, W. L. \& Massung, R. F. (1997). PCR amplification and comparison of nucleotide sequences from the groESL heat shock operon of Ehrlichia species. J Clin Microbiol 35, 2087-2092.

Sumner, J. W., Storch, G. A., Buller, R. S., Liddell, A. M., Stockham, S. L., Rikihisa, Y., Messenger, S. \& Paddock, C. D. (2000). PCR amplification and phylogenetic analysis of groESL operon sequences from Ehrlichia ewingii and Ehrlichia muris. J Clin Microbiol 38, 2746-2749.

Uehara, K. \& Miyoshi, M. (1999). The surface-connected canalicular system in the sinus endothelial cells of rat spleen. Cell Tissue Res 296, 439-442.

Yamaguchi, N., Tipton, V. J., Keegan, H. L. \& Toshioka, S. (1971). Ixodes ovatus Neumann, 1899. Brigham Young Univ Sci Bull Biol Ser 15, 135-142. 